\title{
Modelling Twitter conversations in \#favela towards the conceptualization of the eVoice of the unheard
}

$\mathrm{AQ}: \mathrm{au}$ AQ: 1

\author{
Alessandro Inversini
}

Ecole Hoteliere de Lausanne, Lausanne, Switzerland

Nigel Williams

Department of Business School, Bournemouth University, Poole, UK

\author{
Isabella Rega
}

School of Communication, Bournemouth University, Poole, UK, and

Ioanna Samakovlis

Bournemouth University, Poole, UK
AQ: 2 generating recommendations for organizations and governments acting at the socio-economic level.

\section{Abstract}

Purpose - Social media are seen as a powerful tool for fostering interactive peer-to-peer communication for socio-economic analysis in the field of communication for development. This research has been designed to shed light on the power of social media to harvest and understand socially-motivated discussions towards

Design/methodology/approach - The study presents a large-scale analysis of social media interactions on the topic "\#favela" to generate insights into a social network structure, narrative contents and meaning generated.

Findings - Structurally, the analysed networks are comparable with those presented in current academic literature; automatic text analysis confirmed the promise of the inner value of communication for development opening the floor to conceptualization of the "eVoices of unheard", which is the collective and conscious use of social media to mediate community discussions about tangible and intangible issues related to socio-economic development.

Originality/value - Framed within the rise of interactive communication for development this research show that social media an support the notion of voice proposed by Couldry (2010) moving from process (i.e. the recording of the voice) towards value (i.e. the possibility of giving an account of one's life and its conditions to have an impact on human life and resources) thereby understanding intangible issues related with socio-economic development.

Keywords Semantic similarity, Social media, Social network analysis, eVoices, \#Favela

Paper type Research paper

\section{Introduction}

Although research on social media has been very popular in social sciences, such as marketing (Godey et al., 2016) and politics (Eddington, 2018), it is argued here that an understanding of user-generated content aggregation can also transform and enhance research about socio-economic development, informing policies and interventions (Blazquez and Domenech, 2018). In fact, social media users are part of a digital network and they

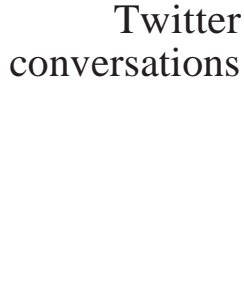

Received 5 September 2019 Revised 9 December 2019 27 January 2020 Accepted 29 January 2020 
participate in different conversations based on interest, clustering around the so-called "communities of interest" (Papadopoulos et al., 2012). Previous studies pointed out how this form of digital communication can provide insights into socially-motivated discussions (Inversini et al., 2015) as a catalyst for social change for the advocacy of social issues (Isa and Himelboim, 2018) and support for marginalized communities (Dagron and Tufte, 2006). Whoever participates in these conversations shares issues relevant to/for the community (at large) and engages with each other on this basis (Siapera et al., 2018) rather than on a commercial basis, as in marketing (Chu and Kim, 2011).

In emerging markets, it has been acknowledged that social media support local forms of expression (Gallaugher and Ransbotham, 2010) thus widening the possibility of people, who are generally "unheard" (i.e. whose opinions are not relevant for decision-makers) to have a forum for discussion; this ultimately gives voice (Siapera et al., 2018) to marginalized people to eventually influence decisions that could affect their lives (Tacchi, 2012). In Brazilian favelas (the context of the study), social media platforms are seen as tools used to promote democratic and inclusive discussions (Nemer, 2016) because they provide an interactive mean for stimulating conversations, information search and, ultimately, residents' engagement. Community dwellers can have a voice through social media hampering the possibility to be part of the decision-making process related to their lives (Tacchi, 2008). This is theoretically in line with the work of Couldry (2010) to which this work aims at contributing to Couldry (2010) in fact, distinguishes between voice as a process (i.e. the network analysis, its actors, etc.) and voice as a value (i.e. topics discussed within digitally hosted communities - Couldry, 2010): authors claim that the study of social media (from a structural point of view and from a semantic point of view) could impact the understanding of process and value, and consequently, trigger actions towards valuing the opinions of the marginalized to support the organization of human life and resources.

To investigate these aspects, this paper builds on related research of social network structures (Williams et al., 2015) and social media narratives (Kozinets et al., 2010), as well as on the call for multi-disciplinary research in the field of social media analysis and unstructured data (Chang, 2018). Methodologically, this is in line with the claim of Lipizzi et al. (2016), who called for a more holistic view of social media analysis, essentially combining structural analysis with a lexical one to shed light on the structure, as well as on content/meaning.

This research undertakes a large-scale analysis based on one year's public conversations on twitter.com mentioning the hashtag \#favela. While existing research has suggested that social media may be less critical than traditional media (Laurell and Sandström, 2018), it is here argued that social media can host a number of relevant discussions. This work proposes the conceptualization of the "eVoice of the unheard", a new construct that extends current understanding of user-generated content aggregation towards a more holistic view of social media as a mediator of socially-motivated discussion in urban places.

\section{Literature review}

2.1 The concept of voice

Lister (2004) defines "voice" as the right to participate in decision-making across social, economic, cultural and political spheres and as a crucial human and citizenship right and a critical component in our understanding of what constitutes poverty. Tacchi (2008) reinforces this definition by adding that "voice poverty" can be understood as the denial of the right of people to influence decisions that affect their lives and the right to participate in that decision-making. The notion of voice helps in overcoming the reductionist interpretation of development (i.e. achieving material progress) to look more into 
subjectively felt (Siapera et al., 2018) and relational well-being (Tacchi, 2012). Therefore, the notion of "voice" can be understood as a multidimensional construct linked with a variety of dimensions of development (Couldry, 2010). One relevant example of the application of the "voice" concept to a developing context is the World Bank Publication "Voices of the Poor" (Narayan-Parker, 2000), which gathered poor and marginalized people's views on poverty. Common characteristics of voicelessness relate to the concepts of powerlessness, dependency and humiliation framed within an own psychological dimension of poverty. These characteristics are related to the concept of marginalization that is defined broadly here as involving exclusion from participation in normal spheres of social life, leading to a state of economic, cultural or political deprivation (Wong et al., 2007).

Voice is about the agency to represent oneself and the right to express an opinion (Tacchi, 2012). As in Couldry (2010), the concept of voice can be understood both as a process and as a value; process refers to the possibility of giving an account of one's life and its conditions whilst value refers to the act of valuing and choosing to value those frameworks for organizing human life and resources that themselves value voice. Therefore, the value should be considered as an end rather than a means of voice Tacchi (2008). So far, there has been interesting in the basic act of voice, not the wider reasons for valuing voice (Tacchi, 2012). It is, therefore, imperative that the act of valuing and choosing to value those frameworks for organizing human life and resources themselves value voice as "open social arrangements" (Smith and Elder, 2010).

The concept of voice is deeply rooted in the body of knowledge of communication for development (Waisbord, 2008), which sees communication as participatory processes for social change and dialogue as key to socially-inclusive processes (Fraser and Villet, 1994).

For communication in general and in communication for development, the advent of digital media has shifted the communication paradigm towards participatory and interactive communication models (Hoffman and Novak, 1996; Selwyn, 2004). There is growing evidence (Dagron and Tufte, 2006) that marginalized groups are using a range of digital platforms to challenge dominant perspectives on their political and cultural identity. Loader and Mercea, (2011) highlight that digital communication at a minimum plays a disruptive role, "challenging traditional interests and modes of communicative power". Digital media particularly allow marginalized groups to reach out across international boundaries to agencies (government and non-government) to publicize their predicament and garner support for action that addresses the conditions that cause their marginalization (Castells, 2013).

Participatory and interactive communication promote horizontal models of development rather than vertical, one-way, top-down or trickledown models more suited to modernization and economic growth approaches to development (Servaes, 2007; Waisbord, 2008). Although modernization and diffusion models of development and of development communication are generally considered to be outdated (Waisbord, 2008), they still appear to guide policy and practice (Mansell, 2011). One other important issue related to communication models in development is the key aspect of listening (Honneth, 1996). To follow Couldry (2010), it is crucial to listen to voice(s) to move from process to value; in fact, development communication and, particularly, the concept of voice requires recognition.

Digital social networks and hosted conversations (i.e. social media - O'Reilly, 2007) offer for the first time the unprecedented opportunity to listen and analyse interactive conversations in different domains, including politics (Kruikemeier, 2014), travel and tourism (Hays et al., 2013), product environments, including goods and services (Tsagkias et al., 2011) and organization in general (Mangold and Faulds, 2009). Anecdotal evidence is present in the literature about research discussing social media content and structure 
(Lipizzi et al., 2016) in a social context (Akaev et al., 2017). However, scant research has considered social media as a tool to listen to those marginalized and act accordingly (Siapera et al., 2018; Blazquez and Domenech, 2018), leveraging the power of social media to create real value for marginalized communities (Couldry, 2010).

\subsection{The rise of social media}

Social media sites host and distribute text, images and video content created by users (Parent et al., 2011). This information may not only be factual but also include opinions and rumours (Dellarocas, 2003) shared with a variety of different publics. By overcoming space and time constraints (Holt, 2016), social media sites enable small, geographically-distributed groups of users to create and maintain discussions on niche and controversial topics (Kaplan and Haenlein, 2010), generating digital crowd-cultures (Holt, 2016). Academics and practitioners alike see social media as a new collaborative tool (Godey et al., 2016). Existing research studies on social media have used methodologies that include surveys and interviews (Phua et al., 2017) for investigating concepts related to users' perceptions, motivation and propensity towards a given subject (Leung et al., 2013). More recent research has started to examine social media postings directly (Lahuerta-Otero and CorderoGutiérrez, 2016) to understand the topic or the network context of social media conversations (Lu and Stepchenkova, 2015).

In the latter domain and building on communication theories, Kozinets et al. (2010) provided a framework to describe social media conversation (using the lens of e-word-ofmouth - Hennig-Thurau et al., 2004) being influenced by four important factors. These are:

(1) Social media conversations being generally embedded in "character narratives" or enduring personal stories;

(2) Communications taking place and being embedded in a given forum and/or digital location;

(3) The actual communication being affected by norms regulating the given communication space; and

(4) The message being affected by the product or service under discussion (Kozinets et al., 2010).

From a network perspective (Ahn et al., 2007), social media contribute to creating communities of interest (Brown and Duguid, 2001). Moving from this perspective, Williams et al. (2015) described social media hosted conversations and the communities created by the participants in terms of size (volume of the conversations), span (pattern of topic engagement) and scope (geographic range of engaged stakeholders). Most of the academic research in this field has failed to merge the network, content and meaning dimensions (Lipizzi et al., 2016); there is, therefore, a call to bridge this gap methodologically.

\subsection{Social media in emerging markets}

Social media platforms can be seen as tools for promoting democratic and inclusive discussions in emerging market contexts (Nemer, 2015). Previous research in developing contexts examined the impact of social media in politics and riots (Pang and Ng, 2016). It has been reported that social media had an influence on Egypt's revolution because the former Egyptian President, Mubarak, shut down the internet in the whole nation for 5 days in 2011 and that YouTube played a crucial role in Iranian Elections in 2009 (Ali, 2011). More instrumental use of social media, especially twitter.com, was reported within the Little India Riot in Singapore, in which the social network played a critical role in updating the 
population about the evolution of the riot (Pang and Ng, 2016). Monroy-Hernández and Spiro (2013) gave an account of Brazilian protests in 2013 by collecting 1.5 million tweets in 20 days and analysing the content and structure of the created networks. Results showed the high activity of the top 1 per cent of users re-posting protest-relevant content in networks with cyclic behaviour. However, there is an open discussion about the role of social media during political unrest. Commentators have viewed the role of social media in these episodes in different ways. On one side, Khondker (2011) praised the role of social media in light of the absence of an open media and a civil society, whereas, on the other side, Fuchs (2012, p. 383) argues that "social media has become a new fetishism of technology that distracts from the contradictions of capitalism underlying contemporary societal changes and conflicts".

Social media can be classified as non-traditional sources of social and economic data that needs the internet for working (Blazquez and Domenech, 2018). Even if there is increasing penetration of the internet in almost every social and economic activity, there is, however, a call for a nuanced view on social media and Web 2.0 in a developing country context (McLennan, 2015). The emancipatory promises of social media are also questioned critically as those who face social and digital marginalization have yet to experience them (Nemer, 2016). A country's economic circumstances, which result in differences in disposable income, can result in differing usage levels of social media (Ali, 2011). This has been mitigated somewhat by the development of new business models, such as pre-paid internet usage and state/non-profit organizations' intervention to improve internet access (Aksoy et al., 2013) via, for example, community-based multimedia telecentres, community technology centres AQ: 3 (CTCs) and LAN houses (Rega et al., 2013).

Nonetheless, social media provide the unprecedented possibility to listen to marginalized people's socially motivated discussions (Inversini et al., 2015), thus understanding tangible and intangible issues related with their life, their community and, ultimately, local socioeconomic development (Pimmer et al., 2012). As a virtual public space, social media can function in multiple roles outside of the sharing of commercial information about brands or eWOM, which can be influenced by country context (Rauchfleisch and Kovic, 2016). Social media can build a collective identity in users who share and comment on a given content (Dobusch and Schoeneborn, 2015). They can be seen as a catalyst to support local forms of expression, thereby widening the possibility of marginalized people having a forum and voice for discussion (Nemer, 2015). This will help in overcoming the reductionist interpretation of development (i.e. achieving material progress) to look more into subjectively felt and relational well-being (Tacchi, 2012).

\subsection{The context of the study}

Brazilian favelas have witnessed a dramatic expansion of digital technology usage (Nemer, 2013). Pew Research Institute reported a growing adoption rate for the internet in Brazil, from 49 per cent in 2013 to 70 per cent in 2017 (pewresearch.org, 2018); however, Nemer (2016), who conducted an ethnographic enquiry in Brazilian informal settlements, confirmed that as Neri (2012) suggested, only a small portion of favela residents are effectively connected to the internet. Nevertheless, there are active CTCs and LAN houses where residents use connections to surf the web and, especially, use social media (Nemer, 2016). Favela residents are conscious and active social media users (Nemer, 2015) and their use of technology goes beyond the functional and utilitarian frame of modern development paradigms. In Nemer's (2016) research, social media were seen as sources of inspiration, training and well-being promotion, as well as a tool to overcome social deprivation. Within the social media landscape, Twitter seems to be one of the major social networks used in the country; following Statista (2019), Brazil ranks as the seventh country worldwide for twitter 
users (8.15 million). Twitter is popular in the country both for its open structure, which allows direct communication and contact with popular figures (Fastenberg, 2010) and for its ease of use as a communication tool during political unrest and riots (Monroy-Hernández and Spiro, 2013).

However, as Kleine (2010) maintains, empowerment is achieved when people are able to choose their desired outcome; social media can, therefore, represent an initial step in the community empowerment process. This research uses the \#favela to identify conversations about Brazilian informal settlements in general without looking specifically at any of them.

\section{Research design}

Framed within the rise of interactive communication for development (Selwyn, 2004), the overarching aim of this research is to understand if social media and, in particular, twitter. com can support the notion of voice proposed by Couldry (2010). This involves moving from the process (i.e. the recording of the voice) towards value (i.e. the possibility of giving an account of one's life and its conditions to have an impact on human life and resources), thereby understanding intangible issues related with socio-economic development (Pimmer et al., 2012). This will be achieved following Lipizzi et al. (2016) notion of integrating structure, content and meaning in social networking analysis by deeply engaging with a network (Williams et al., 2015) and communication (Kozinets et al., 2010) perspectives. The research proposed the direct investigation of social media postings (Lu and Stepchenkova, 2015) to examine the use of social media (Nemer, 2016) in a developing country context. Data obtained from non-traditional socio-economic sources are generally large, heterogeneous and unstructured or semi-structured (Blazquez and Domenech, 2018); despite their potential for treating socio-economic data, the application of analysis and mining techniques in the socio-economic development field, is still at an early stage.

To tackle this issue, this research moves from the work of Blazquez and Domenech (2018), who highlighted the need for using non-traditional, unstructured (big) data to inform socio-economic research. The study presents a large-scale analysis of social media interactions for the topic "\#favela" (Nemer, 2016) on twitter.com. Conversations presenting the hashtag "\#favela" were archived using the online service Netlytics.com. Twitter.com is popular in Brazil (Brazil is the seventh country by twitter.com user base - Statista, 2019) and even if it does not have the largest base of social media users, it has particular strengths for this research area. These are:

- Twitter.com updates do not require significant online bandwidth, making it accessible to individuals with limited or intermittent access to the internet, such as underprivileged groups;

- the default option for Twitter.com posts is "public", which enables any user to interact with content supporting multiple modes of communication that incorporate individual and group information interactions. These two features enable the creation of various discussion groups of variable size and the "real-time" nature of twitter.com supports the creation of discussions about events, such as protests, as they unfold (Kwak et al., 2010); and

- Twitter.com provides access to historical data and metadata that enable an analysis of online discussions generated at a particular point in time later.

\subsection{Research methodology}

3.1.1 Social network analysis. Social media like twitter.com, create virtual social communities (Shu and Chuang, 2011) by enabling information-sharing and interpersonal 
relationship ties of varying strength between users (Etzioni, 1998). More active users having frequent contacts with others are considered strong ties, whereas weak ties tend to have unidirectional, less frequent contact with other members (Gilbert and Karahalios, 2009). Strong ties tend to dominate information exchange within network subgroups or clusters whilst weak ties connect sub-groups or clusters, facilitating information distribution (Haythornthwaite, 2001). In the social media environment, norms and expectations for communications are heavily influenced by users with stronger ties, i.e. influencers in social media marketing (Lindsay et al., 2015), which can shape the structure and content of the network (DeSanctis and Poole, 1994) and can support the process of diffusion of dominant meanings. The structure and content/meaning of twitter.com discussions can be examined from interaction or network perspectives, known as social network analysis (SNA) (Hansen et al., 2010). SNA has been used in various fields such as management (Sedereviciute and Valentini, 2011), sociology (Mützel, 2009) and international development (Friend and Rapport, 1991) to examine relationships between entities. For business and management research, SNA applications fall into two domains. The first stream attempts to explain the influence of social networks on real-world outcomes such as social capital theory (Antoniadis and Charmantzi, 2016). The second domain uses SNA as a means to identify and visualize patterns of interactions among users to identify the influence on information flow and, hence, communication (Culotta and Cutler, 2016). SNA has also been used to examine the influence of relational ties on the diffusion of e-WoM (Hennig-Thurau et al., 2004) on social media (Lee et al., 2013) and the roles particular actors perform in sharing review data (Hinz et al., 2014). It is expected that the network formed by the actor in this context will feature both personalities and organizations as nodes on the network (Williams et al., 2015).

3.1.2 Automated text analysis. While network approaches can provide insight on interactions between entities, they do not provide a deep analysis of the content of interactions (Inversini et al., 2015). Content in twitter.com can take the form of unstructured text data and can provide an additional understanding of social media discussions (Carley and Palmquist, 1992). Furthermore, as in Lipizzi et al. (2016), the study of meaning within communities of interest can give additional insights, enhancing content and structure studies. Common social media discussion topics and narratives, such as politics (McPherson et al., 2001), news (Tsagkias et al., 2011), entertainment (Atefeh and Khreich, 2015) and products and services (Chevalier and Mayzlin, 2003), are likely to appear in the analysis. However, twitter.com data can be unstructured and difficult to understand using text approaches that merely attempt to count the frequency of keywords. This issue can be addressed by using additional approaches adopted from network analysis (Diesner and Carley, 2010) to understand not only keyword frequency but also to examine semantic interconnectivity among concepts (Carley and Palmquist, 1992). Narrative study in the form of network analysis can be performed on text data to identify patterns of word and language usage that can then be classified. In this form of analysis, words and their forms are considered "nodes" and lexical distance between them or co-occurrences can be modelled as links (van Meter and de Saint Léger, 2008). These networks can then be clustered into "lexical worlds" (Lebart et al., 1998) that can be examined to identify emergent topics of discussions in unstructured text.

\subsection{Research questions}

Theoretically, this paper moves from the work of Couldry (2010) and Tacchi (2012). The indepth analysis of social media conversations (i.e. structures of conversations, hedges of communities of interest and specific theme discussions) will support a more specific view of 
topics discussed (i.e. what communities care about) and their relative size and opinion leaders (i.e. how big are communities of interest and who are the opinion leaders). This will give a more nuanced view of the needs and wants of the communities and will help in ranking the importance of them. In accordance with Tacchi (2012), this will overcome a reductionist approach to development, enhancing the value of voice (Couldry, 2010). As network structures can influence information flow (Gomez Rodriguez et al., 2013), the differences in online network structures may generate an understanding of information sharing and communication strategies (Hanna et al., 2011). The first question is, therefore:

RQ1. What is the variation of network structure by language type?

Similarly, research has examined the type of entities considered to be key influencers (Lindsay et al., 2015) and whose content is more likely to be observed by network participants (Kim et al., 2014). However, research has not examined them by language type or any temporal variations. In this paper, these users will be identified by the network metric of betweenness centrality, which indicates potential brokers or individuals, who act as an informational bridge between clusters in the network (Scott et al., 2008). For this research, the top 10 users in each network in RQ1 and RQ2 were identified by betweenness centrality. The profile of each of these users was reviewed and a classification framework adapted from Wu et al. (2011) was applied to categorize users. Therefore, the second research question is:

RQ2. What are the types of key influencers by language type and season?

Additionally, moving from communication and narrative perspective (Kosinets et al., 2010) and from the construct of "voice" elaborated by Tacchi (2012), the research looks into the semantic similarity (Eddington, 2018) of the two networks in terms of the topic discussed. The research demonstrated that socially motivated conversation may appear generally if stimulated by organizations (Inversini et al., 2015) or if social movements find in social media a possibility of expression (Isa and Himelboim, 2018).

Therefore, the last research question is:

RQ3. What are the differences in terms of topics of conversations between insiders (i.e. people living in the favela) and outsiders (i.e. people visiting the favela)?

\subsection{Data collection and filtering}

Tweets with the hashtag "\#favela" were collected for a period of one year using Netlytics. com. In the current research, it is quite common to find single hashtag analysis (Stewart et al., 2017) to explore the use of social media in a given context for a given purpose (Carroll, 2018). Authors acknowledge that this could be a simplistic approach but, considering the scale and complexity of the conversation, it was sufficient to investigate the aim and research questions at stake. Based on the peculiarities of twitter.com outlined above (i.e. low bandwidth needed, public nature of the content, metadata associated with the content), the present research used:

- Time zone metadata; and

- Language as a proxy to filter the data collected for the hashtag \#favela.

Time zone metadata was used to capture conversations containing the hashtag \#favela that originated from Brazil to avoid discussions about the term happening in other countries with other meanings. The remaining tweets were separated by language into two different 
groups: the Portuguese language (people living in the favela) and the English language (people visiting the favela). Although this choice can trigger criticism (because of the fact that favela dwellers can also use the English language to communicate on Twitter), it seemed the most natural way to segment two different types of actors in the communication process, as twitter metadata were poor in creating users' profiles.

To prepare the sample for the two analyses (i.e. SNA and text analysis), two different F1 filtering operations have been made (See Figure 1 for details).

(1) To identify the information network of users, interactions in the form of retweets, replies and mentions were identified (Stieglitz and Dang-Xuan, 2012), an approach used in previous works (Yardi and Boyd, 2010). This filtering technique allowed filtering only interactions among network participants. These were then modelled as a directed graph using SNA (Gephi) and statistics were calculated to identify the overall structural characteristics and key users by network metrics. The text of Twitter profiles for these key users were then reviewed to identify their characteristics.

(2) Automatic text analysis has been designed to generate a broad understating of the richness of the topic discussed rather than looking at the main (i.e. popular) discussions. To this end, duplicate tweet content (i.e. retweets are a piece of content semantically similar to original tweets) was removed to avoid bias related to popular conversations (i.e. music songs, twitter.com popular hashtags). This is consistent with previous work (Ratinaud and Marchand, 2015) and essential to shed light on the diverse range of topics discussed and on the breadth of subjects debated within the medium. Automatic text analysis was conducted using Iramuteq (www.iramuteq.org/) with the semantic similarity analysis technique (belonging to social representation theory - Levidow and Upham, 2017). This was developed by Flament (1981) to investigate the proximity and relations among elements of a given cluster. It does so by calculating a contingency coefficient between the elements of the cluster, which is called a similarity index (Flament, 1981). The semantic similarity analysis has, as output, a connected and cyclical graph (the maximum tree of the system), in which all elements are linked together and there is only one way to move from one element to another (Clemence et al., 2014). Additional operations carried out on the corpus to facilitate text mining regarded the cancellation of text strings referring to URLs, videos and images, as well as user names, to gain pure data.

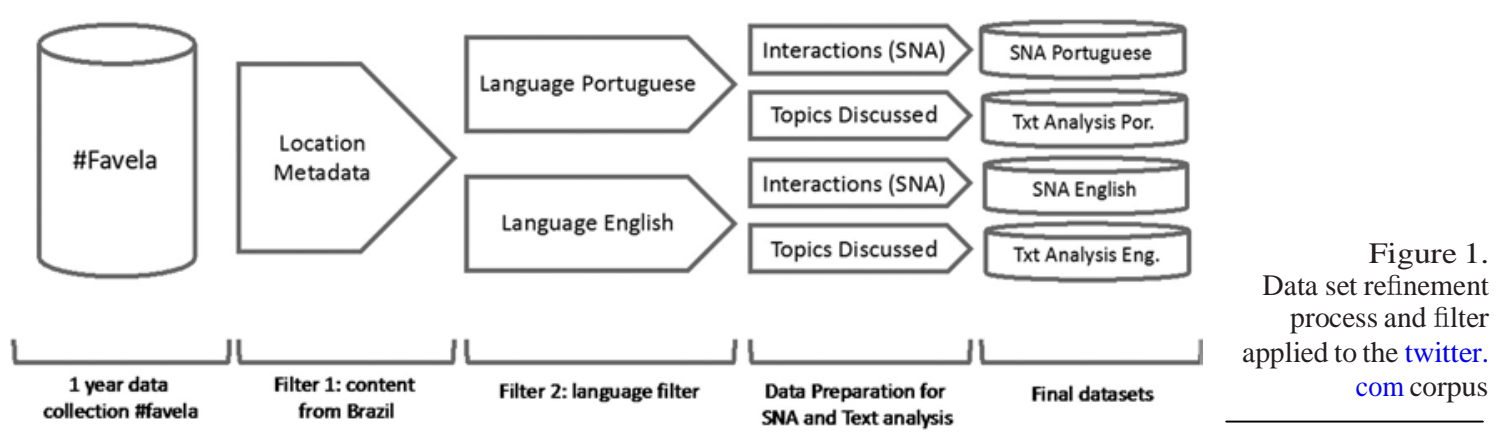




\section{JICES}

Figure 1 proposes the different steps to reach the final samples analysed in the research. The final sample for SNA contained a total of 1,344,165 tweets (1,037,766 Portuguese p 131,835 English). The final sample for text analysis contained a total of 1,722,015 tweets $(1,529,931$ Portuguese p 192,084 English).

\section{Results}

\subsection{Network structure (RQ1)}

Tables I and II present an overview of the twitter.com networks by language; networks were analysed on a three by three-month basis (i.e. seasons) because of the huge number of edges and because of popular events taking place in Brazil (i.e. Carnival). The Portuguese networks are significantly larger than the English networks with significantly higher network diameter and path lengths, which suggests information may propagate more slowly through Portuguese language networks (Ahn et al., 2007). The high modularity suggests the existence of sub-communities that may have distinct interests (Zaglia, 2013). Figure 1 presents, as an example, the illustration of the English language network subcommunities and the connections among them.

While the English language networks exhibit relatively little variation over time, the Portuguese language networks exhibit high seasonal variation. The network scale varies from a low of 102,632 users to a high of 166,355 for the periods starting June and September, respectively. Furthermore, the March-May period exhibited a significant fall in network diameter and average path length. This finding may reflect a relative lull in online activity after the carnival period of peak tourism and domestic cultural activities (DecemberFebruary).

The English and Portuguese language networks have significant differences in total edges, network diameter and path length. As the diameters and average path lengths of the Twitter networks are relatively high, it suggests they may not be small-world networks, further suggesting that these networks have scale-free properties similar to other real-world networks (Bild et al., 2015). Large twitter networks with low centralization and a high average path length have been classified previously as fragmented (brand) clusters

Table I.

English language

network's description

\begin{tabular}{lcccc}
\hline English language networks & December-February & March-May & June-August & September-November \\
\hline Vertices & 16,762 & 14,773 & 14,875 & 13,734 \\
Total edges & 17,252 & 30,912 & 26,892 & 24,115 \\
Network diameter & 23 & 27 & 29 & 23 \\
Average path length & 8.075654 & 9.075129 & 9.111104 & 9.265306 \\
Modularity & 0.880111 & 0.89495 & 0.517104 & 0.518022 \\
Centralization & 0.0804 & 0.070 & 0.018 & 0.06 \\
\hline
\end{tabular}

\begin{tabular}{lcccc}
\hline Portuguese language networks & December-February & March-May & June-August & September-November \\
\hline Vertices & 114,300 & 114,950 & 102,632 & 166,355 \\
Total edges & 151,208 & 121,244 & 106,203 & 183,985 \\
Network diameter & 68 & 32 & 48 & 52 \\
Modularity & 0.941 & 0.923 & 0.928 & 0.895 \\
Average path length & 21.603 & 9.638 & 15.112 & 14.361 \\
Centralization & 0.062 & 0.006 & 0.009 & 0.010 \\
\hline
\end{tabular}


(Himelboim et al., 2013). As indicated by the high modularity, they are a collection of diverse interests that communicate within distinct topic groups but not across them. These properties are also maintained across seasons, which suggests the relatively small number of individuals with high centrality scores can attract interest in these networks. These individuals can be named "influencers" (Kim et al., 2014) within the networks; it is, therefore, possible for them to reach users in both the English and Portuguese language networks.

\subsection{Types of influencer (RQ2)}

A small number of individuals holding power positions within a network may be able to shape the conversation within it (Lindsay et al., 2015) by posting or re-posting a series of contents they find relevant. Prominent individual accounts for the English network are US music celebrities, ordinary individuals and English language media; the Portuguese network includes Brazilian celebrities, Brazilian NGOs, Brazilian online media and ordinary individuals. This is not surprising as most social media and twitter.com research had similar findings showing these individuals discussing political issues (Stieglitz and DangXuan, 2012), entertainment topics (Souza et al., 2016) and sharing opinions about products and services (Chevalier and Mayzlin, 2003). The structural characteristics of these networks, however, limit the extent of influence of a single individual account. The low centralization and high average path length suggest that multiple connections are required to reach the entire network. The networks (English and Portuguese) may be sustained by the interactions among them. Further, the high modularity indicates that distinct subgroups exist that may not interact with each other. These findings indicate that the Portuguese and English favela networks may be hosts to a variety of discussions, which will be discussed in the next section.

\subsection{Text analysis (RQ3)}

Text units were reduced into their original form before being separated into active forms and auxiliary forms (Ratinaud, 2013). Data were grouped visually according to the vicinity in which the words occur most frequently by using semantic similarity analysis (Clemence AQ: 5 et al., 2014). Similar approaches were already used in the literature; for example, Eddington (2018) applied a similar technique to study the network around US elections. Graphs F2 F3 (Figures 2 and 3) present the clusters of lemmas in accordance with semantic similarity analysis and quotes from the twitter data set have been cherry-picked in an explorative way to give more substance to the explanation of results.

4.3.1 Semantic similarity analysis of the Portuguese data set. The Portuguese data set, when taken in its entirety, is dense (1,529,931 original tweets). Attempts were made to reduce the complexity of the entire data set into major evident clusters (Figure 2). These were identified as a funk, music and culture cluster (funk, música and cultura) shared by the community (comunidade). A series of tweets with cultural and community value (especially related to the carnival) can be found:

[.. . ] carnaval vai descer a favela toda [The entire favela will go to the Carnival]. and

[.. . ] o lado bom de morar na favela e que sempre tem pessoa louca retarda, sempre tem alegria em meio de tanta coisa ruim e sempre tem samba [The good side of living in the favela is that there is always a crazy person, always in the middle of all the bad things and always samba].

Once more, a cluster around associations and representations is made with the notion of a house and home (casa) and the cluster of the pauper (pobre), in combination with his 


\section{JICES}

Figure 2.

Portuguese cluster for all seasons: similarity analysis

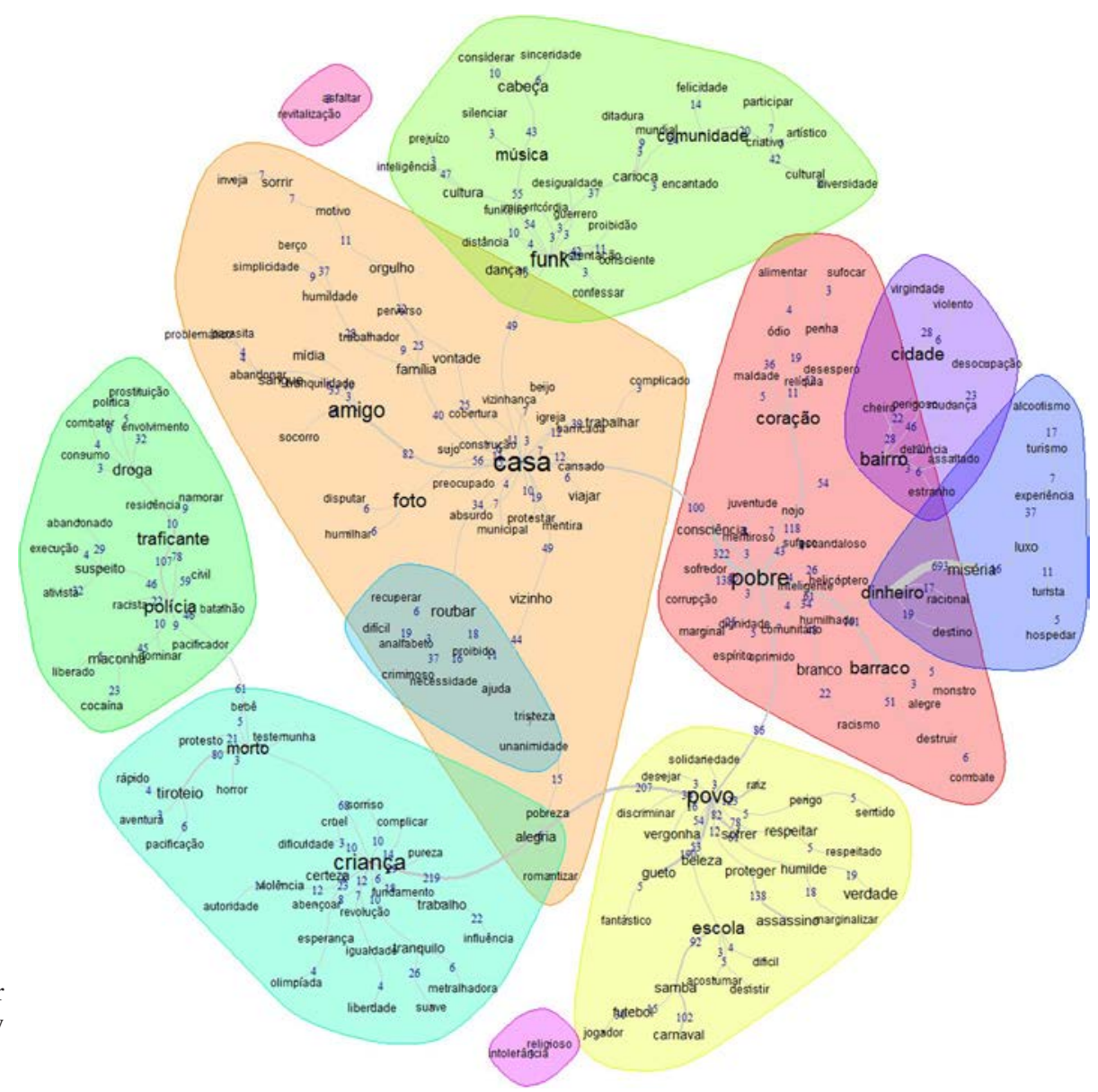

homestead (barraco), which is under threat of being destroyed (destruir); this was also related with the Olympic Games (i.e. RIO 2016, taking place near the favela).

Favela começou a demolição apesar dos protestos dos moradores [Demolishing the favela began despite protests by residents].

Additionally, a pobre (poor person) cluster emerges as a povo (people and citizen) cluster form, with associations of being humble (humilde), helpful (socorro - help) and the favela as a refuge for those amongst them who are discriminated against (discriminar). Especially, the notion of humble people and a humbling experience of going to a favela can be found frequently:

Caminhar por uma favela é uma experiência de humildade é um ambiente muito complexo e em constante mudança [Walking through a favela is an experience of humbleness; it is a very complex environment and in constant change].

and 


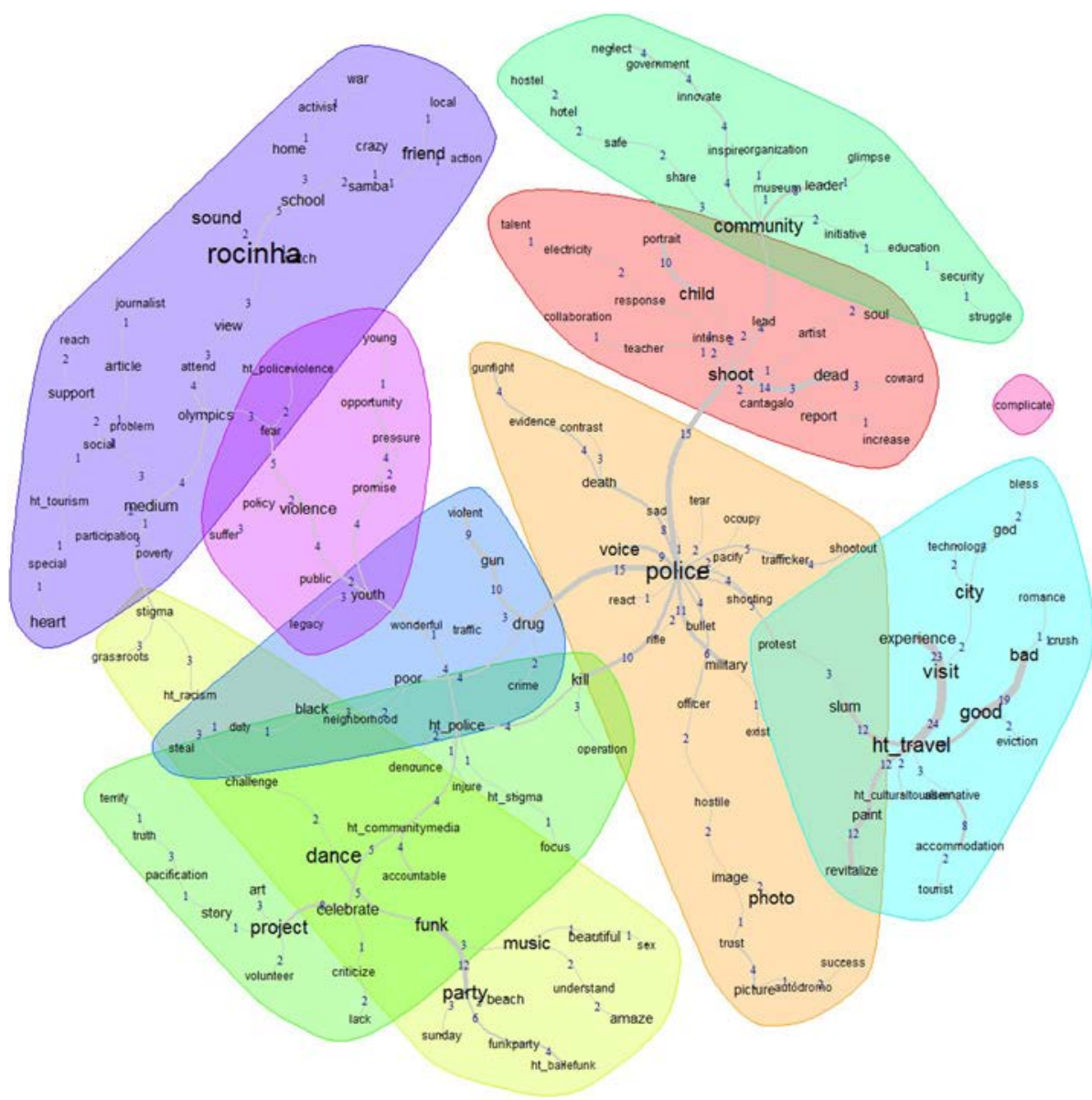

Figure 3.

English cluster for all seasons: similarity analysis

Não quero dizer que là não existe tristeza não quero dizer que là não existe pobreza porque favela sem miséria nao é favela [I don't want to say that sadness doesn't exist; I don't want to say poverty doesn't exist because a favela without misery is not a favela].

A very distinct cluster of money (dinheiro) also emerges, ascribing different connotations to it. On the one hand, it enables fleeing from misery but it is also associated with alcohol (álcool) abuse and immoral gain:

[...] os ricos fazem campanha contras as drogas mais pro outro lado promovem e ganham muito dinheiro com o alcool que é vendido na favela [The rich campaign against drugs but, on the other hand, they promote and gain a lot of money from the alcohol sold in the favela].

Moreover, solidarity, beauty and respect, as well as refuge from discrimination from others, creates humble (humilde) people (povo) in the favela. Out of this community, the upbringing of children has a complexity of its own related to these conditions. Thus, a criança (child) is associated not only with joy (alegría), purity (pureza) and sorriso (smile) but also with hardship (dificuldade) and the fear of someone's life being cut short in a gunfight (tiroteio). 
The criança cluster (child cluster) contains and represents values such as comunidade (community) and esperança (hope), as well as positive and negative connoted words such as sorriso (smile) and sofrimento (suffering), respectively. A smaller cultura-cluster comprises aspects of education (educação) and intelligence (intêligencia), as well as a compromise (compromise).

As one can see, tweets related to these clusters indicate the complexity and interrelatedness of these concepts, connecting childhood, joy and despair:

[... . olho o sorriso da criança que na favela não tem mais esperança de viver tranquilamente [I see the smile of a child who does not have any hope of living peacefully in a favela].

[.. . ] sorriso estampadao no rosto dando um rôle na favela [A smile embossed on the face is giving a role to the favela].

Gunfights are related to the police/trafficker (policía/traficante) and comprise drugs (droga), prostitution (prostitução) and execution (execução) in the cluster. Finally, in this presentation of data, tourism (turismo, turista) emerges as a cluster by itself; however, as is evident, the association with a notion of misery (miséria), which appears throughout the different seasons, did not change.

A branch concerning (sex) tourism and relating to tourism and alcoholism can be found within this cluster:

[...] terra do alcoolismo favela domínio de um turismo sexual [land of alcoholism: favela - a dominion of sex tourism].

From the analysis of the Portuguese data, it can be said that the favela seems to be the living environment for most of the people contributing to this data set, which is reflected in the multitude, diversity and complexity of this data set. As in real life, all aspects of life are represented and interrelated.

4.3.2 Semantic similarity analysis of the English data set. Looking at the depiction of all data in the English data set (192,084 original tweets), it can be said a clear tourism and travel cluster is found, comprising items related to Rocinha (Figure 3). Brazil has hosted several mega events and media outlets reported in English. In relation to resisting re-housing plans to make room for Olympic buildings, a cluster around \#vilaautödromo (the favela demolished to accommodate new Olympic buildings) has emerged. Additionally, other clusters include only a discourse about Rocinha, a group to remove stigmata from the favela, as well as a cluster around the term "paint", representing an initiative to paint favela walls:

Painting revitalizing \#brazil slums \#travel \#ttot \#riodejaneiro \#expatlife.

Community local Facebook page coordinator launches \#crowdfunding campaign to paint walls in \#complexodoalemão.

In relation to this, an additional cluster was formed around funk and music related to tourism:

[... ] favela funk party every Sunday night, we take you there \#bealocaltours \#bealocal funkparty \#bailefunk.

A police violence cluster was formed, as well as a cluster containing notions around drug trafficking. This cluster can mostly be explained as being the result of news websites' reporting rather than tourists posting their perceptions: 
News: this morning residents and police reported a shooting in \#morrodafallet, a Santa Teresa community with a \#upp.

\section{Twitter conversations}

Central to the clusters is that items relating to the police are concentrated, such as the military, pacification, shooting, shoot-outs and death. This leads to clusters similar to the Portuguese clusters of childhood and community, with topics within the child cluster revolving around shootings. The community cluster indicates different projects stabilising this community through education, security and own initiatives. Furthermore, the exploratory analysis of the discussions and discourses generated within the two networks reveals digital dialogue about politics (Bastos et al., 2013), entertainment (Atefeh and Khreich, 2015), products and services (Chevalier and Mayzlin, 2003) and, eventually, socially-motivated discussions (Inversini et al., 2015). This enabled the researchers to discuss the similarity of the two networks in terms of topics debated.

Finally, for the English cluster, it can be said that despite travel and leisure time clusters representing a major share of the tweets, discussions on civic engagement, injustice and other issues relating to the everyday life worlds of favela residents can also be identified. Therefore, both differences and similarities with the Portuguese data set can be found.

\section{Discussion and conclusions}

This research was designed to harness the power of social media in a given developing context to understand intangible issues related to socio-economic development (Pimmer et al., 2012) in a given community. This was done primarily to support the promise of interactive communication for development (Selwyn, 2004) towards generating a better understanding of the concept of "eVoice of unheard", which can give tangible and intangible recommendations to inform policies and interventions in marginalized communities (Couldry, 2010).

The research moved from the study of social media that is very popular in several disciplines but particularly in marketing (Godey et al., 2016) and politics (Eddington, 2018) above all. However, they could help in supporting local socio-economic development by flagging up issues that are not directly visible and/or explicated. Social media can definitively support a more nuanced view of the needs and wants of local communities by coupling text analysis with network analysis. In accordance with Tacchi (2012), this will overcome a reductionist approach to development, enhancing the value (Couldry, 2010) of voice.

The research was built around twitter.com conversations in an emerging market and methodologically tackled the syntactic analysing (i.e. structure) of the network (Williams et al., 2015) and the semantic (i.e. content) of the narratives (Kozinets et al., 2010) by focussing on internal and external network perspectives (Lipizzi et al., 2016). In total, 12 months' twitter.com conversations under the hashtag \#favela were collected. Language (i.e. English and Portuguese language) and geolocalization (tweets from Brazil) were used as a proxy to create two samples; within those samples, two network-based analyses were performed. The first concerned the metadata of information connections aimed at understanding the network structure and the role of key influencers (SNA), whilst the second enquiry (semantic similarity analysis) aimed at discovering the main topics discussed within the networks.

From a structure perspective, the analysed networks present the same characteristics of networks already presented in the literature (Gomez Rodriguez et al., 2013; Himelboim et al., 2017). However, additional insights can be driven by moving from the $3 S$ framework presented by Williams et al. (2015): 


\section{JICES}

(3)

$$
\text { netwoln }
$$
networks. However, socially-motivated discussions emerge in both languages (Inversini et al., 2015), confirming Nemer's (2016) claim related to the responsible use of digital technologies, especially social media, as well as supporting the notion of voices elaborated by Tacchi (2012).

Following (Kozinets et al., 2010) characteristic of social media discussion, the analysed corpus clearly presents and gives meaning to personal stories of favela dwellers in a given digital location. Additionally, results from the semantic similarity analysis and from the network analysis also confirmed that the communication and topic discussed are deeply affected by norms regulating the given communication space (retweet and mention Kozinets et al., 2010). What is slightly different from Kozinets et al. (2010) discussion is the fact that analysed messages are not only affected by product and/or service but also actually reflect social issues and highlight the presence of socially-motivated discussions (Inversini et al., 2015).

The aggregation of these socially motivated discussions led to the conceptualization of the "eVoice of the unheard". This concept adds an additional layer to the previously discussed concept of voice (Couldry, 2010; Tacchi, 2012) fostering the possibility of constantly and lively listen to the needs of marginalized communities. In fact, social media host non-traditional forms of data (Blazquez and Domenech, 2018) that if properly analysed can serve as an amplifier for marginalized communities by providing an online space for discussion and engagement. This enables locals to attract attention and sustain conversations among publics and counter publics (Jackson and Foucault Welles, 2015) about crucial issues of socio-economic development.

In fact, if, on one side, the analysed conversations appear to have similar psychological boundaries and motivations with respect to the ones highlighted by Narayan et al. (1999), on the other side, data retrieved from social media are less structured with respect to data purposefully collected (as in the case of Narayan-Parker, 2000). However, social media data are richer as the conversations develop bottom-up and users do cluster around specific subjects and interests.

The concept of "eVoice of the unheard" promotes horizontal and participative models to inform polices and intervention for socio-economic development (Servaes, 2007). Social media, offer an interactive listening deck providing the possibility of voice to have an impact within the community (Couldry, 2010). Therefore, by coupling structural analysis (e.g. SNA) with semantic analysis, "eVoice of the unheard" expresses the depth and breadth of digital 
and interconnected narratives posted on social media to generate a better understanding of the voice of given communities.

Finally, this study has some limitations that need to be acknowledged. Firstly, although penetration and adoption of digital technologies are growing in developing and rural areas, not all individuals have access to these media; therefore, eVoice of the unheard should be treated as a representation of the needs and wants of the communities. However, it is acknowledged that no strategy could capture all voices within a community. Secondly, although there could ethical concerns about social media discussion harvesting (Williams et al., 2017), the authors believe that twitter.com provides content published to the internet "at large" and with no complex privacy settings to bypass (Bruns et al., 2012). Therefore, the authors believe that publicly accessible and anonymized information does not bridge any AQ: 6 ethical issues (Zimmer and Proferes, 2014).

\section{References}

Ahn, Y.-Y., Han, S., Kwak, H., Moon, S. and Jeong, H. (2007), "Analysis of topological characteristics of huge online social networking services", Proceedings of the 16th International Conference on World Wide Web, pp. 835-844. doi: 10.1145/1242572.1242685.

Akaev, A., Korotayev, A., Issaev, L. and Zinkina, J. (2017), “Technological development and protest waves: Arab spring as a trigger of the global phase transition?", Technological Forecasting and Social Change, Vol. 116, pp. 316-321, doi: 10.1016/j.techfore.2016.08.009.

Aksoy, L., van Riel, A., Kandampully, J., Bolton, R.N., Parasuraman, A., Hoefnagels, A., . . Komarova Loureiro, Y. (2013), "Understanding generation Y and their use of social media: a review and research agenda", Journal of Service Management, Vol. 24 No. 3, pp. 245-267.

Ali, A.H. (2011), "Power of social media in developing nations: new tools for closing the global digital divide and Beyond", Harvard Human Rights Journal, Vol. 24, p. 185.

Antoniadis, I. and Charmantzi, A. (2016), "Social network analysis and social capital in marketing: theory and practical implementation", International Journal of Technology Marketing, Vol. 11 No. 3, pp. 344-359.

Bastos, M.T., Raimundo, R.L.G. and Travitzki, R. (2013), "Gatekeeping Twitter: message diffusion in political hashtags", Media, Culture and Society, Vol. 35 No. 2, pp. 260-270, doi: 10.1177/ 0163443712467594.

Bild, D.R., Liu, Y., Dick, R.P., Mao, Z.M. and Wallach, D.S. (2015), "Aggregate characterization of user behavior in twitter and analysis of the retweet graph", ACM Transactions on Internet Technology (Technology), Vol. 15 No. 1, p. 4.

Blazquez, D. and Domenech, J. (2018), "Big data sources and methods for social and economic analyses", Technological Forecasting and Social Change, Vol. 130, pp. 99-113, doi: 10.1016/j. techfore.2017.07.027.

Brown, J.S. and Duguid, P. (2001), "Knowledge and organization: a Social-Practice perspective", Organization Science, Vol. 12 No. 2, pp. 198-213, doi: 10.1287/orsc.12.2.198.10116.

Bruns, A. Burgess, J.E. Crawford, K. and Shaw, F. (2012), “\#qldfloods and @QPSMedia: crisis communication on twitter in the 2011 South East Queensland floods [report]", Retrieved from ARC Centre of Excellence for Creative Industries and Innovation, Queensland University of Technology website, available at: https://eprints.qut.edu.au/48241/

Carley, K. and Palmquist, M. (1992), "Extracting, representing, and analyzing mental models", Social Forces, Vol. 70 No. 3, pp. 601-636.

Carroll, D.R. (2018), "\#Palestine2Ferguson a community created through words", Journal of Information, Communication and Ethics in Society, Vol. 16 No. 3, pp. 328-337, doi: 10.1108/JICES03-2018-0026. 
Castells, M. (2013), Communication Power, OUP Oxford.

Chevalier, J.A. and Mayzlin, D. (2003), "The effect of word of mouth on sales: online book reviews (working paper no. 10148)", Retrieved from National Bureau of Economic Research website, available at: www.nber.org/papers/w10148

Chu, S.-C. and Kim, Y. (2011), "Determinants of consumer engagement in electronic word-of-mouth (eWOM) in social networking sites", International Journal of Advertising, Vol. 30 No. 1, pp. 47-75, doi: 10.2501/IJA-30-1-047-075.

Clemence, A., Doise, W. and Lorenzi-Cioldi, F. (2014), The Quantitative Analysis of Social Representations, Routledge, New York, NY.

Couldry, N. (2010), Why Voice Matters - Culture and Politics after Neoliberalism, Sage Publications. Thousand Oaks, CA.

Culotta, A. and Cutler, J. (2016), "Mining brand perceptions from twitter social networks", Marketing Science, Vol. 35 No. 3, pp. 343-362.

Dagron, A.G. and Tufte, T. (2006), Communication for Social Change Anthology: Historical and Contemporary Readings, CFSC Consortium, NJ.

Dellarocas, C. (2003), "The digitization of word of mouth: Promise and challenges of online feedback mechanisms", Management Science, Vol. 49 No. 10, pp. 1407-1424, doi: 10.1287/ mnsc.49.10.1407.17308.

DeSanctis, G. and Poole, M.S. (1994), "Capturing the complexity in advanced technology use: adaptive structuration theory", Organization Science, Vol. 5 No. 2, pp. 121-147.

Diesner, J. and Carley, K.M. (2010), “A methodology for integrating network theory and topic modeling and its application to innovation diffusion", IEEE, pp. 687-692.

Dobusch, L. and Schoeneborn, D. (2015), "Fluidity, identity, and organizationality: the communicative constitution of anonymous", Journal of Management Studies, Vol. 52 No. 8, pp. 1005-1035.

Eddington, S.M. (2018), "The communicative constitution of hate organizations online: a semantic network analysis of "make America great again", Social Media p Society, Vol. 4 No. 3, doi: 10.1177/2056305118790763.

Etzioni, A. (1998), The New Golden Rule: Community and Morality in a Democratic Society, Basic Books, New York, NY.

Fastenberg, D. (2010), "Why is twitter so popular in Brazil?", Time. 20 October, available at: http:// content.time.com/time/world/article/0,8599,2026442,00.html

Flament, C. (1981), "L'analyse de similitude: Une technique pour les recherches sur les représentations sociales [Similarity analysis: a technique for researches in social representations]", Cahiers de Psychologie Cognitive/Current Psychology of Cognition, Vol. 1 No. 4, pp. 375-395.

Fraser, C. and Villet, J. (1994), "Communication: a key to human development", available at: http://agris. fao.org/agris-search/search.do?recordID=XF9546741

Friend, A.M. and Rapport, D.J. (1991), "Evolution of macro-information systems for sustainable development", Ecological Economics, Vol. 3 No. 1, pp. 59-76, doi: 10.1016/0921-8009(91)90048-J.

Fuchs, C. (2012), "Social media, riots, and revolutions", Capital and Class, Vol. 36 No. 3, pp. 383-391, doi: $10.1177 / 0309816812453613$.

Gallaugher, J. and Ransbotham, S. (2010), "Social media and customer dialog management at Starbucks", MIS Quarterly Executive, Vol. 9 No. 4, pp. 197-212.

Gilbert, E. and Karahalios, K. (2009), "Predicting tie strength with social media", Proceedings of the SIGCHI Conference on Human Factors in Computing Systems, pp. 211-220, available at: https:// doi.org/10.1145/1518701.1518736

Godey, B., Manthiou, A., Pederzoli, D., Rokka, J., Aiello, G., Donvito, R. and Singh, R. (2016), "Social media marketing efforts of luxury brands: influence on brand equity and consumer behavior", Journal of Business Research, Vol. 69 No. 12, pp. 5833-5841, doi: 10.1016/j.jbusres.2016.04.181. 
Gomez Rodriguez, M., Leskovec, J. and Schölkopf, B. (2013), "Structure and dynamics of information pathways in online media", Proceedings of the Sixth ACM International Conference on Web Search and Data Mining, pp. 23-32, doi: 10.1145/2433396.2433402.

\section{Twitter conversations}

Hanna, R., Rohm, A. and Crittenden, V.L. (2011), "We're all connected: the power of the social media ecosystem", Business Horizons, Vol. 54 No. 3, pp. 265-273., doi: 10.1016/j.bushor.2011.01.007

Hansen, D., Shneiderman, B. and Smith, M.A. (2010), Analyzing Social Media Networks with NodeXL: Insights from a Connected World, Morgan Kaufmann, Burlington.

Hays, S., Page, S.J. and Buhalis, D. (2013), "Social media as a destination marketing tool: its use by national tourism organisations", Current Issues in Tourism, Vol. 16 No. 3, pp. 211-239, doi: 10.1080/13683500.2012.662215.

Haythornthwaite, C. (2001), "Tie strength and the impact of new media", International Conference on System Sciences, Presented at the Hawaii, Hawaii.

Hennig-Thurau, T., Gwinner, K.P., Walsh, G. and Gremler, D.D. (2004), "Electronic word-ofmouth via consumer-opinion platforms: what motivates consumers to articulate themselves on the internet?", Journal of Interactive Marketing, Vol. 18 No. 1, pp. 38-52, doi: 10.1002/dir.10073.

Himelboim, I., Smith, M. and Shneiderman, B. (2013), "Tweeting apart: applying network analysis to detect selective exposure clusters in twitter", Communication Methods and Measures, Vol. 7 Nos 3/4, pp. 195-223, doi: 10.1080/19312458.2013.813922.

Himelboim, I., Smith, M.A., Rainie, L., Shneiderman, B. and Espina, C. (2017), "Classifying twitter topicnetworks using social network analysis", Social Media p Society, Vol. 3 No. 1, doi: 10.1177/ 2056305117691545.

Hinz, O., Schulze, C. and Takac, C. (2014), "New product adoption in social networks: why direction matters", Journal of Business Research, Vol. 67 No. 1, pp. 2836-2844.

Hoffman, D.L. and Novak, T.P. (1996), "Marketing in hypermedia computer-mediated environments: conceptual foundations", Journal of Marketing, Vol. 60 No. 3, p. 50.

Holt, D. (2016), "Branding in the age of social media", Harvard Business Review, Vol. 94 No. 3, p. 13.

Honneth, A. (1996), The Struggle for Recognition: The Moral Grammar of Social Conflicts, MIT Press, New York, NY.

Inversini, A., Sage, R., Williams, N. and Buhalis, D. (2015), "The social impact of events in social media conversation", in Tussyadiah I. and Inversini A. (Eds), Information and Communication Technologies in Tourism, Lugano, pp. 283-294, doi: 10.1007/978-3-319-14343-9_21.

Isa, D. and Himelboim, I. (2018), "A social networks approach to online social movement: Social mediators and mediated content in \#FreeAJStaff twitter network", Social Media p Society, Vol. 4 No. 1, doi: $10.1177 / 2056305118760807$.

Jackson, S.J. and Foucault Welles, B. (2015), "Hijacking \#MYNYPD: social media dissent and networked counterpublics", Journal of Communication, Vol. 65 No. 6, pp. 932-952, doi: 10.1111/jcom.12185.

Kaplan, A.M. and Haenlein, M. (2010), "Users of the world, unite! The challenges and opportunities of social media", Business Horizons, Vol. 53 No. 1, pp. 59-68, doi: 10.1016/j.bushor.2009.09.003.

Khondker, H.H. (2011), "Role of the new media in the Arab Spring", Globalizations, Vol. 8 No. 5, pp. 675-679, doi: 10.1080/14747731.2011.621287.

Kim, S.J. Pai, S. Bickart, B.A. and Brunel, F.F. (2014), "How social media influencers build a brand following by sharing secrets (SSRN scholarly paper no. ID 2549040)", Retrieved from Social Science Research Network website, available at: http://papers.ssrn.com/ abstract $=2549040$

Kozinets, R., de Valck, K., Wojnicki, A.C. and Wilner, S. (2010), "Networked narratives: understanding word-of-mouth marketing in online communities", Journal of Marketing, Vol. 74 No. 2, pp. 71-89, doi: $10.1509 / j m k g .74 .2 .71$. 
Kruikemeier, S. (2014), "How political candidates use Twitter and the impact on votes", Computers in Human Behavior, Vol. 34, pp. 131-139, doi: 10.1016/j.chb.2014.01.025.

Lahuerta-Otero, E. and Cordero-Gutiérrez, R. (2016), "Looking for the perfect tweet. The use of data mining techniques to find influencers on twitter", Computers in Human Behavior, Vol. 64, pp. 575-583, doi: 10.1016/j.chb.2016.07.035.

Laurell, C. and Sandström, C. (2018), "Comparing coverage of disruptive change in social and traditional media: evidence from the sharing economy", Technological Forecasting and Social Change, Vol. 129, pp. 339-344, doi: 10.1016/j.techfore.2017.09.038.

Lebart, L., Salem, A. and Berry, L. (1998), "Cluster analysis of words and texts", Exploring Textual Data, Springer, New York, NY pp. 81-100.

Lee, H., Lee, D.I., Kim, T. and Lee, J. (2013), "The moderating role of socio-semantic networks on online buzz diffusion", Journal of Business Research, Vol. 66 No. 9, pp. 1367-1374.

Leung, D., Law, R., van Hoof, H. and Buhalis, D. (2013), "Social media in tourism and hospitality: a literature review", Journal of Travel and Tourism Marketing, Vol. 30 Nos 1/2, pp. 3-22, doi: 10.1080/10548408.2013.750919.

Levidow, L. and Upham, P. (2017), "Socio-technical change linking expectations and representations: innovating thermal treatment of municipal solid waste", Science and Public Policy, Vol. 44 No. 2, pp. 211-224, doi: 10.1093/scipol/scw054.

Lindsay, A., Kaykas-Wolff, J. and Mathwick, C. (2015), "Key influencers: locating, measuring, and creating programs to influence social media influencers", in Deeter-Schmelz D.R. (Ed.), Proceedings of the 2010 Academy of Marketing Science (AMS) Annual Conference, pp. 1-1, doi: 10.1007/978-3-319-11797-3_1.

Lipizzi, C., Iandoli, L. and Marquez, J.E.R. (2016), "Combining structure, content and meaning in online social networks: the analysis of public's early reaction in social media to newly launched movies", Technological Forecasting and Social Change, Vol. 109, pp. 35-49, doi: 10.1016/j. techfore.2016.05.013.

Lister, R. (2004), Poverty, Polity Press, Cambridge.

Loader, B.D. and Mercea, D. (2011), "Networking democracy? Information", Communication and Society, Vol. 14 No. 6, pp. 757-769, doi: 10.1080/1369118X.2011.592648.

Lu, W. and Stepchenkova, S. (2015), "User-Generated content as a research mode in tourism and hospitality applications: Topics, methods, and software", Journal of Hospitality Marketing and Management, Vol. 24 No. 2, pp. 119-154, doi: 10.1080/19368623.2014.907758.

McLennan, S.J. (2015), “Techno-optimism or information imperialism: paradoxes in online networking, social media and development", Information Technology for Development, doi: 10.1080/ 02681102.2015.1044490.

McPherson, M., Smith-Lovin, L. and Cook, J.M. (2001), "Birds of a feather: homophily in social networks", Annual Review of Sociology, Vol. 27 No. 1, pp. 415-444.

Mangold, W.G. and Faulds, D.J. (2009), "Social media: the new hybrid element of the promotion mix", Business Horizons, Vol. 52 No. 4, pp. 357-365, doi: 10.1016/j.bushor.2009.03.002.

Mansell, R. (2011), "Power and interests in information and communication and development: exogenous and endogenous discourses in contention", Journal of International Development, Vol. 26 No. 1, pp. 109-127, doi: 10.1002/jid.1805.

Monroy-Hernández, A. and Spiro, E. (2013), "How Brazilian protesters are using twitter", The Guardian, 4 July, available at: www.theguardian.com/news/datablog/2013/jul/04/brazilianprotesters-twitter-microsoft

Mützel, S. (2009), "Networks as culturally constituted processes a comparison of relational sociology and actor-network theory", Current Sociology, Vol. 57 No. 6, pp. 871-887, doi: 10.1177/ 0011392109342223. 
Narayan-Parker, D. (2000), Crying out for Change: Voices of the Poor, World Bank Publications, Washington, DC.

Nemer, D. (2013), Favela Digital: The Other Side of Technology, Editora GSA. Vitoria.

Twitter
conversations

Nemer, D. (2015), "Online favela: the use of social media by the marginalized in Brazil", Information Technology for Development, Vol. 1, pp. 1-16, doi: 10.1080/02681102.2015.1011598.

Nemer, D. (2016), "Rethinking social change: the promises of web 2.0 for the marginalized", First Monday, Vol. 21 No. 6, doi: 10.5210/fm.v21i6.6786.

O'Reilly, T. (2007), "What is web 2.0: Design patterns and business models for the next generation of software (SSRN scholarly paper no. ID 1008839)", Retrieved from Social Science Research Network website, available at: http://papers.ssrn.com/abstract=1008839

Pang, N. and Ng, J. (2016), “Twittering the little India riot: audience responses, information behavior and the use of emotive cues", Computers in Human Behavior, Vol. 54, pp. 607-619, doi: 10.1016/j. chb.2015.08.047.

Papadopoulos, S., Kompatsiaris, Y., Vakali, A. and Spyridonos, P. (2012), "Community detection in social media", Data Mining and Knowledge Discovery, Vol. 24 No. 3, pp. 515-554, doi: 10.1007/ s10618-011-0224-z.

Parent, M., Plangger, K. and Bal, A. (2011), “The new WTP: willingness to participate”, Business Horizons, Vol. 54 No. 3, pp. 219-229, doi: 10.1016/j.bushor.2011.01.003.

pewresearch.org (2018), "Social media use continues to rise in developing countries", Retrieved December 3, 2019, from Pew Research Center's Global Attitudes Project website, available at: www. pewresearch.org/global/2018/06/19/social-media-use-continues-to-rise-in-developing-countries-butplateaus-across-developed-ones/

Phua, J., Jin, S.V. and Kim, J. (2017), "Uses and gratifications of social networking sites for bridging and bonding social capital: a comparison of Facebook, Twitter, Instagram, and Snapchat", Computers in Human Behavior, Vol. 72, pp. 115-122, doi: 10.1016/j.chb.2017.02.041.

Pimmer, C., Linxen, S. and Gröhbiel, U. (2012), "Facebook as a learning tool? A case study on the appropriation of social network sites from mobile phones in developing countries", British Journal of Educational Technology, Vol. 43 No. 5, pp. 726-738, doi: 10.1111/j.14678535.2012.01351.x.

Ratinaud, P. and Marchand, P. (2015), "Des mondes lexicaux aux représentations sociales. Une première approche des thématiques dans les débats à l'Assemblée nationale (1998-2014)”, Mots, No. 108, pp. 57-77.

Rauchfleisch, A. and Kovic, M. (2016), "The internet and generalized functions of the public sphere: transformative potentials from a comparative perspective", Social Media $\mathbf{p}$ Society, Vol. 2 No. 2, doi: 2056305116646393.

Rega, I., Vannini, S., Fino, E. and Cantoni, L. (2013), "Exploring the meanings of community multimedia centers in Mozambique: a social representation perspective", Information Technologies and International Development, Vol. 9 No. 4, pp. 35-54.

Scott, N., Cooper, N.S.R.B.C. and Baggio, R. (2008), Network Analysis and Tourism, Channel View Publications, Bristol.

Sedereviciute, K. and Valentini, C. (2011), "Towards a more holistic stakeholder analysis approach: mapping known and undiscovered stakeholders from social media", International Journal of Strategic Communication, Vol. 5 No. 4, pp. 221-239, doi: 10.1080/ 1553118X.2011.592170.

Selwyn, N. (2004), "Reconsidering political and popular understandings of the digital divide", New Media and Society, Vol. 6 No. 3, pp. 341-362, doi: 10.1177/1461444804042519.

Servaes, J. (2007), Communication for Development and Social Change, SAGE Publications India, New Delhi.

Shu, W. and Chuang, Y. (2011), "The perceived benefits of six-degree-separation social networks", Internet Research, Vol. 21 No. 1, pp. 26-45, doi: 10.1108/10662241111104866. 
Siapera, E., Boudourides, M., Lenis, S. and Suiter, J. (2018), "Refugees and network publics on Twitter: networked framing, affect, and capture", Social Media p Society, Vol. 4 No. 1, doi: 10.1177/ 2056305118764437.

Smith, M. and Elder, L. (2010), "Open ICT ecosystems transforming the developing world”, Information Technologies and International Development, Vol. 6 No. 1, pp. 65-71.

Statista (2019), "Countries with most twitter users 2019", From Statista website, available at: www.statista. com/statistics/242606/number-of-active-twitter-users-in-selected-countries/ (accessed 3 December 2019).

Stewart, L.G., Arif, A., Nied, A.C., Spiro, E.S. and Starbird, K. (2017), "Drawing the lines of contention: networked frame contests within \#BlackLivesMatter discourse", Proceedings of the Acm on Human-Computer Interaction, Vol. 1, pp. 1-96-23, doi: 10.1145/3134920.

Stieglitz, S. and Dang-Xuan, L. (2012), "Political communication and influence through microblogging-an empirical analysis of sentiment in twitter messages and retweet behavior", 45th HI International Conference on System Science (HICSS), pp. 3500-3509, doi: 10.1109/HICSS.2012.476.

Tacchi, J. (2008), "Voice and poverty", Media Development, Vol. 1, p. 1.

Tacchi, J. (2012), "Open content creation: the issues of voice and the challenges of listening", New Media and Society, Vol. 14 No. 4, pp. 652--668, doi: 10.1177/1461444811422431.

Tsagkias, M., de Rijke, M. and Weerkamp, W. (2011), "Linking online news and social media", Proceedings of the Fourth ACM International Conference on Web Search and Data Mining, pp. 565-574, doi: 10.1145/1935826.1935906.

van Meter, K.M. and de Saint Léger, M. (2008), "Co-Word text analysis applied to political science: 2006 international political \& 'parapolitical' headlines", Bulletin of Sociological Methodology/Bulletin de Méthodologie Sociologique, Vol. 97 No. 1, pp. 18-38.

Waisbord, S. (2008), "The institutional challenges of participatory communication in international aid", Social Identities, Vol. 14 No. 4, pp. 505-522, doi: 10.1080/13504630802212009.

Williams, M.L., Burnap, P. and Sloan, L. (2017), “Towards an ethical framework for publishing Twitter data in social research: taking into account users' views, online context and algorithmic estimation", Sociology, Vol. 51 No. 6, pp. 1149-1168, doi: 10.1177/0038038517708140.

Williams, N.L., Inversini, A., Buhalis, D. and Ferdinand, N. (2015), "Community crosstalk: an exploratory analysis of destination and festival eWOM on twitter", Journal of Marketing Management, Vol. 1, pp. 1--28, doi: 10.1080/0267257X.2015.1035308.

Wong, D.F.K., Li, C.Y. and Song, H.X. (2007), "Rural migrant workers in urban China: living a marginalised life", International Journal of Social Welfare, Vol. 16 No. 1, pp. 32-40, doi: 10.1111/ j.1468-2397.2007.00475.x.

Wu, S., Hofman, J.M., Mason, W.A. and Watts, D.J. (2011), Who Says What to Whom on Twitter, ACM, New York, pp. 705-714.

Yardi, S. and Boyd, D. (2010), "Dynamic debates: an analysis of group polarization over time on twitter", Bulletin of Science, Technology and Society, Vol. 30 No. 5, pp. 316-327.

Zaglia, M.E. (2013), "Brand communities embedded in social networks", Journal of Business Research, Vol. 66 No. 2, pp. 216-223, doi: 10.1016/j.jbusres.2012.07.015.

Zimmer, M. and Proferes, N.J. (2014), "A topology of twitter research: Disciplines, methods, and ethics", Aslib Journal of Information Management, Vol. 66 No. 3, pp. 250-261, doi: 10.1108/AJIM-09-20130083.

\section{Further reading}

Zhang, Y., Moe, W.W. and Schweidel, D.A. (2016), "Modeling the role of message content and influencers in social media rebroadcasting", International Journal of Research in Marketing, doi: 10.1016/j.jijresmar.2016.07.003. 


\begin{abstract}
About the authors
Alessandro Inversini is an Associate Professor in Marketing at Ecole hôtelière de Lausanne, HES-SO University of Applied Sciences and Arts Western Switzerland. He is an expert in marketing communication, digital communication and digital marketing with extensive academic and industry experience. He holds a $\mathrm{PhD}$ in Communication Science from the Università della Svizzera italiana (2010) and a Master in Communication Sciences and Communication Technologies in 2004. Alessandro Inversini is the corresponding author and can be contacted at: alessandro.inversini@ehl. ch

Dr Nigel Williams is the Senior Lecturer in Project Management at Bournemouth University and has previously worked at the University of Bedfordshire. Before joining academia, he worked for 15 years as a Project Manager and Business Consultant for manufacturing organizations in the Caribbean Region. Nigel holds a PhD in Engineering from the University of Cambridge. He also holds a BSc in Mechanical Engineering and an MSc in Marketing from the University of the West Indies. His research interests include project and event evaluation using social media, festival internationalization and organizational project management.

Isabella Rega holds a $\mathrm{PhD}$ in Communication Sciences and an Executive Master's degree in Intercultural Communication from the Università della Svizzera Italiana (USI). Her PhD dissertation dealt with the role of telecentres in socio-economic development. She is currently a Principal Lecturer in Digital Technologies and Education at CEMP - Centre of Excellence in Media Practice, Media School, Bournemouth University. She has worked in telecentres, as researcher and instructor, in Jamaica, Burkina Faso, Benin, Guinea and South Africa, and collaborated as an online teacher for a distance learning university in Colombia.

Ioanna Samakovlis holds an MSc in Tourism Management from Bournemouth University, UK (2016). Her research focus lies in digital, offi cial and informal networks, ICT4D, social group formation and social structures on social media and sustainable tourism. She has worked and studied in the tourism industry in the USA and Germany.
\end{abstract}

For instructions on how to order reprints of this article, please visit our website:

www.emeraldgrouppublishing.com/licensing/reprints.htm

Or contact us for further details: permissions@emeraldinsight.com 
